УДК 621.762

Михайлов О. В. Михайлов А. О. Баглюк Г. А. Штефан Е. В.

\title{
ИССЛЕДОВАНИЕ УПЛОТНЕНИЯ И ФОРМОИЗМЕНЕНИЯ ПОРИСТЫХ ЗАГОТОВОК ПРИ ПОЛУЧЕНИИ ИЗДЕЛИЙ С ВНУТРЕННЕЙ КОНУСООБРАЗНОЙ ПОВЕРХНОСТЬЮ
}

В современной промышленности широко применяются детали, имеющие кольцевидную форму. Среди таких изделий отдельную группу составляют детали с конусообразной поверхностью (рис. 1). Изображенная на рисунке деталь применяется в мельнице для размола кофе. Она имеет кольцевидную форму, а верхняя ее часть ограничена конической поверхностью.

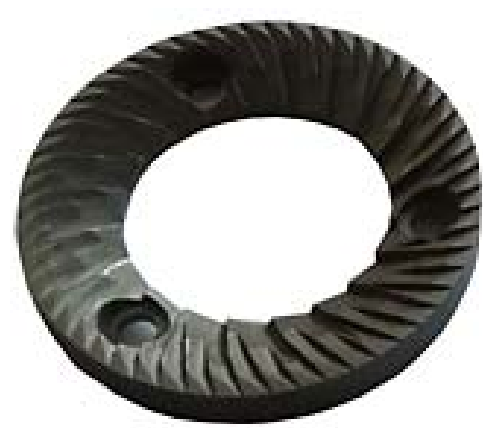
обработки

Рис. 1. Изделие с внутренней конусообразной поверхностью после механической

Эффективными методами изготовления деталей, имеющих кольцевидную форму, являются методы порошковой металлургии, обеспечивающие значительную экономию материала и позволяющие получать изделия с уникальными свойствами. Одним из таких методов является горячая штамповка порошковых пористых заготовок [1-6].

Наиболее широкое промышленное применение получила технологическая схема односторонней осевой деформации в закрытом штампе. В то же время, при реализации этой схемы нужно достаточно точно выдерживать массу исходных заготовок. Сложность получения точных заготовок обуславливает необходимость использовать прессовки с небольшими плюсовыми допусками по массе, а также наличия в конструкции штампа специального компенсатора для размещения избыточного объема металла.

При штамповке в закрытом штампе с минимальной степенью поперечной деформации в заготовке возникают зоны затрудненной деформации, характеризующиеся наличием остаточной пористости. Регулировать распределение плотности в объеме заготовки можно за счет применения схем штамповки с элементами истечения, в штампах с компенсационными полостями.

Конструкция компенсатора должна обеспечивать вытекание излишка металла только на заключительной стадии штамповки. Кроме того, сопротивление вытеканию металла в компенсационную полость должно быть достаточно высоким, чтобы обеспечить полное заполнение штампа и уплотнение материала по всему объему изделия.

Отмеченным требованиям соответствует конструкция штампа для горячей штамповки порошковых заготовок с кольцевым коническим компенсатором [7, 8]. Особенностью конструкции штампа является возможность реализации истечения избытка материала 
на завершающей стадии процесса уплотнения в сужающуюся компенсационную щель, образованную поверхностями конических участков матрицы и пуансона. Коническая форма инструмента предохраняет от возможности заклинивания пуансона в матрице.

Целью работы является определение закономерностей уплотнения и формоизменения пористых заготовок при получении изделий с внутренней конусообразной поверхностью методом штамповки в штампе с кольцевым коническим коипенсатором.

Установление этих закономерностей экспериментальными методами является трудоемким и дорогостоящим процессом. Поэтому целесообразно использовать метод предварительного компьютерного моделирования.

Моделирование выполнено на основе континуального подхода. В качестве определяющих соотношений использовали соотношения теории пластичности пористого тела, представляющие собой обобщение существующих эллипсоидальных моделей [9].

Уравнение поверхности нагружения (текучести) принимается в виде:

$$
F=\frac{\left(p-p_{0}\right)^{2}}{\psi}+\frac{\tau^{2}}{\varphi}-\tau_{s}^{2}=0
$$

где $p_{0}$ - значение шаровой компоненты напряженного состояния, при которой объем пористого материала не изменяется. Размер полуосей эллипсоидального контура принимается зависящим от $p$ :

$$
\left\{\begin{array}{c}
\psi=\psi_{1} \quad \text { при } p \leq p_{0} \\
\psi=\psi_{2} \quad \text { при } p>p_{0} .
\end{array}\right.
$$

Величины функций $\varphi, \psi$ и $p_{0}$ равны:

$$
\begin{gathered}
\varphi=\frac{1}{(1+m)^{2}} \cdot(1-\theta)^{3} \cdot(1-|2 \cdot a-1|)^{2}, \\
\psi_{1}=\frac{8}{3} \cdot \frac{(1-\theta)^{4}}{\theta} \cdot \frac{(1-a)^{2}}{(1+m)^{2}}, \\
\psi_{2}=\frac{8}{3} \cdot \frac{(1-\theta)^{4}}{\theta} \cdot \frac{a^{2}}{(1+m)^{2}}, \\
p_{0}=\sqrt{\frac{2}{3}} \cdot \tau_{s} \cdot \frac{(1-\theta)^{2}}{\sqrt{\theta}} \cdot\left(\frac{1-m-2 \cdot a}{1+m}\right),
\end{gathered}
$$

где, наряду с пористостью $\theta$ и приведенным напряжением течения твердой фазы $\tau_{S}$, входят два параметра $a$ и $m$, изменяющиеся в диапазонах $0 \leq a \leq 1,0 \leq m \leq 1$. Параметр $a$ характеризует хрупкость материала частиц пористого тела, $m$ - качество контактов между частицами.

Для одного из случаев сочетания материальных параметров положение контура нагружения приведено на рис. 2.

Если $a=0,5$ и $m=0$, представленная модель превращается в модель типа $[10,11]$, которая используется для описания поведения связанных пористых тел. При $a=0,5$ и $m=1$, 
соотношения (1)-(6) соответствуют модели Cam - Clay, описывающей несвязанные дисперсные системы. Случай $0 \leq m \leq 1$ соответствует спеченным пористым материалам, содержащим несовершенные контакты. При $0 \leq a \leq 0.5$ и $m=0$ получаем модель [12].

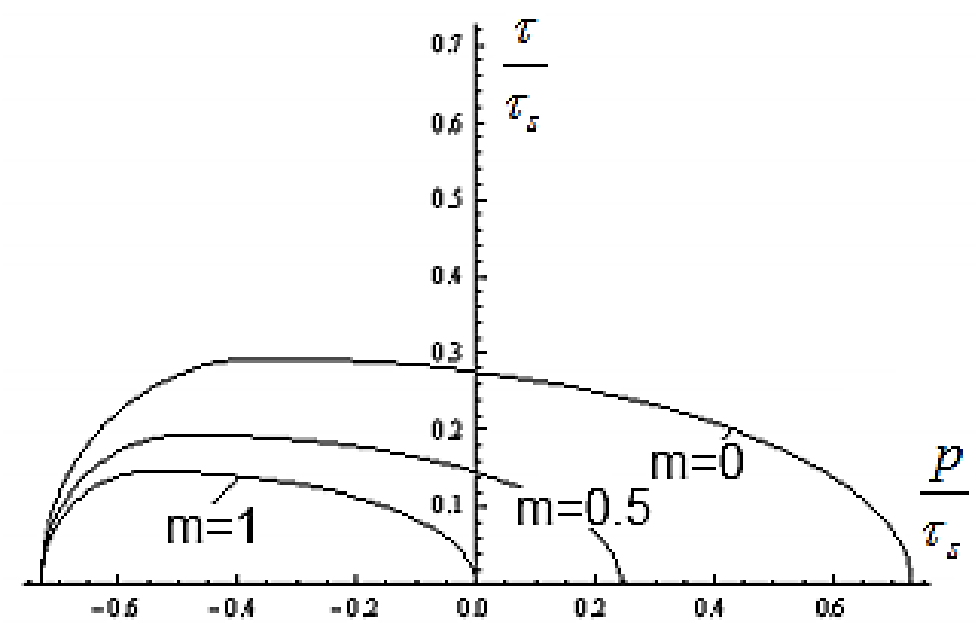

Рис. 2. Контуры поверхности нагружения при различных значениях материального параметра $m(a=0,75, \theta=0,3)$

Определение формы штампуемой заготовки, а также полей плотности, напряжений и деформаций выполнено на основе метода конечных элементов [13].

На рис. 3 представлены форма штампуемого изделия (а) и схема деформирования (б). Схема деформирования предусматривает наличие радиального течения материала, что дает возможность повысить эксплуатационные свойства получаемых изделий [14].

Размеры изделия были следующими: внутренний диаметр 32 мм, наружный диаметр 54 мм, внутренняя высота 6 мм и наружная высота 11 мм.

Начальная заготовка имела форму полого цилиндра. Внутренний ее диаметр равнялся диаметру иглы и был равен 32 мм. Наружный диаметр менялся и принимал значения 49,6 мм и 52 мм. Соответственно, высоты равнялись 14,35 мм и 12,27 мм.

Величина начальной пористости заготовки $\theta_{0}=0,2$, материал ее твердой фазы - сталь.

Также рассматривалась штамповка биметаллических заготовок. При этом высота верхнего (более прочного) слоя равнялась одной трети общей высоты заготовки. Материал верхнего слоя - легированная сталь. При моделировании полагали, что предел текучести верхнего слоя выше предела текучести нижнего слоя в два раза.

Игла, нижний пуансон и матрица были неподвижны. Деформирование заготовки происходило за счет перемещения верхнего пуансона. На заключительной стадии штамповки между верхним пуансоном и матрицей остается зазор, в который вытекает излишний металл. Коэффициент трения между заготовкой и инструментом принимали равным 0,15.

Наличие зазора между наружной боковой поверхностью заготовки и матрицей обеспечивает течение материала в радиальном направлении от центра. Такое направление течения материала приводит к ному, что деформируемая заготовка достигает зоны компенсатора в конце штамповки, и таким образом минимизируются потери материала.

В связи с симметрией в дальнейшем рассматривается правая половина осевого сечения штампуемой заготовки.

На рис. 4 приведены результаты моделирования штамповки заготовки, начальные свойства которой были одинаковы по всему обьему.

В начальный момент штамповки происходит уплотнение порошкового материала в верхней части заготовки около ее внутренней поверхности. Деформируемый материал течет в радиальном направлении от центра. Нижняя часть внутренней поверхности заготовки отходит от иглы. 
При дальнейшем перемещении верхнего пуансона процесс уплотнения распространяется на остальные области деформируемого изделия. Наружная поверхность заготовки достигает поверхности матрицы, при этом внутренняя ее поверхность полностью контактирует с иглой. Начинается вытекание металла в полость компенсатора (пространство между верхним пуансоном и матрицей). Распределение пористости на этом этапе неравномерно. Минимальная пористость по прежнему в верхней части заготовки у ее внутренней поверхности. С увеличением радиуса величина пористости возрастает. Максимальная пористость соответствует области вытекания материала. Кроме того, менее интенсивно материал уплотняется в нижней части заготовки у ее наружной и внутренней поверхностей.

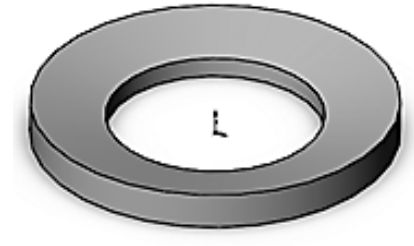

a

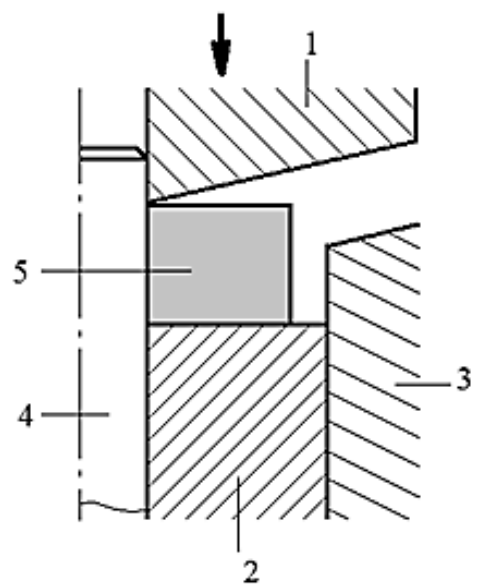

б

Рис. 3. Порошковое изделие (а) и схема деформирования (б):

1 - верхний пуансон; 2 - нижний пуансон; 3 - матрица; 4 - игла; 5 - порошковая заготовка

На заключительной стадии штамповки материал полностью заполняет полость штампа, происходит доуплотнение зон затрудненной деформации и выравнивание плотности по объёму изделия. При этом излишек металла вытекает в облой. Небольшое уменьшение плотности наблюдается в нижней части заготовки у наружной поверхности.

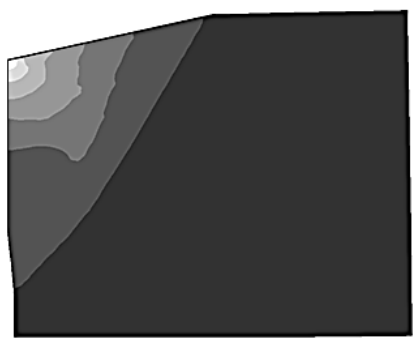

a

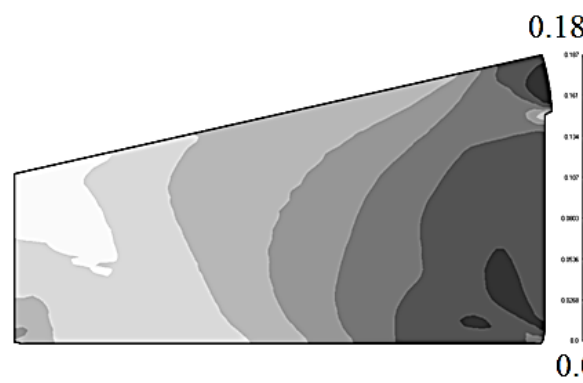

B

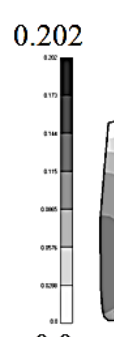

0.0

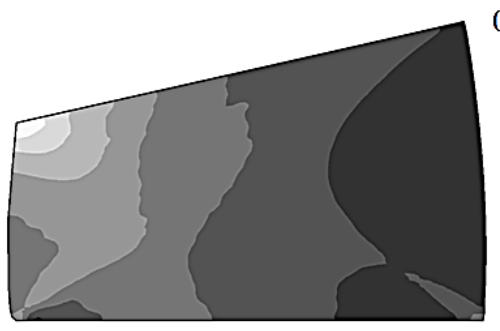

6

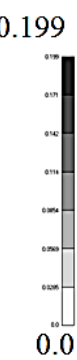

0.0

0.147

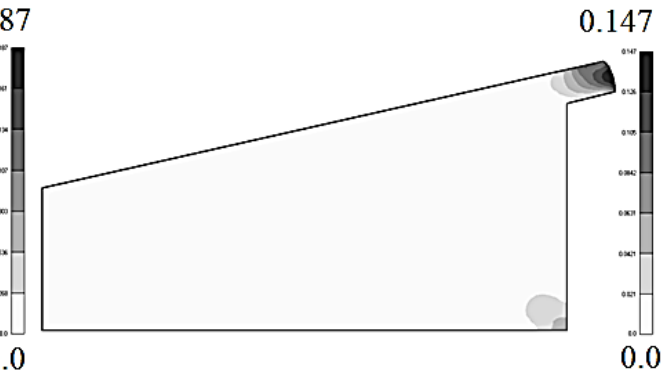

$\Gamma$

Рис. 4. Распределение пористости на последовательных этапах (а, б, в, г) штамповки заготовки, начальные свойства которой были одинаковы по обьему $\left(\theta_{0}=0,2\right)$ 
При штамповке биметаллической заготовки начальная пористость слоев была одинаковой $\left(\theta_{0}=0,2\right)$. Нижний слой, материал твердой фазы которого имеет более низкий предел текучести, уплотняется более интенсивно. Происходит вдавливание более прочного верхнего слоя в менее прочный нижний слой. Это приводит к вытеканию нижнего слоя из-под верхнего. В результате получить требуемое биметаллическое изделие не представляется возможным.

Для предотвращения вытекания материала нижнего слоя из-под верхнего слоя было предложено использовать заготовки с разной начальной пористостью слоев.

На рис. 5 приведены результаты уплотнения такой биметаллической заготовки. Предел текучести твердой фазы верхнего слоя был выше, чем предел текучести твердой фазы иижнего слоя. При этом величина пористости верхнего слоя была выше (равнялась 0,3), а нижнего слоя - ниже (равнялась 0,15).

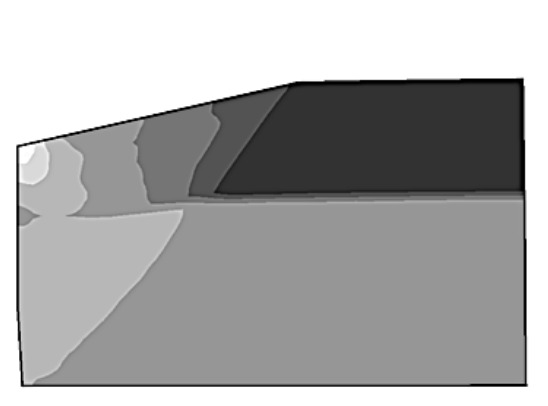

a

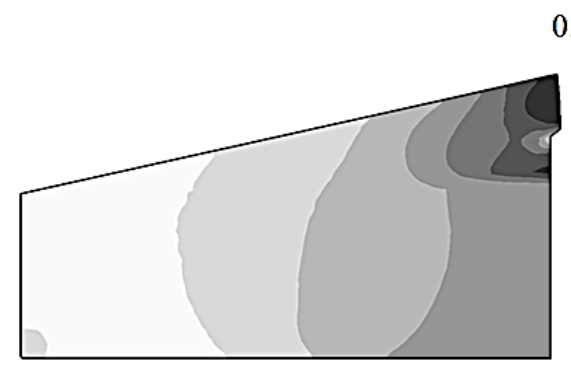

B
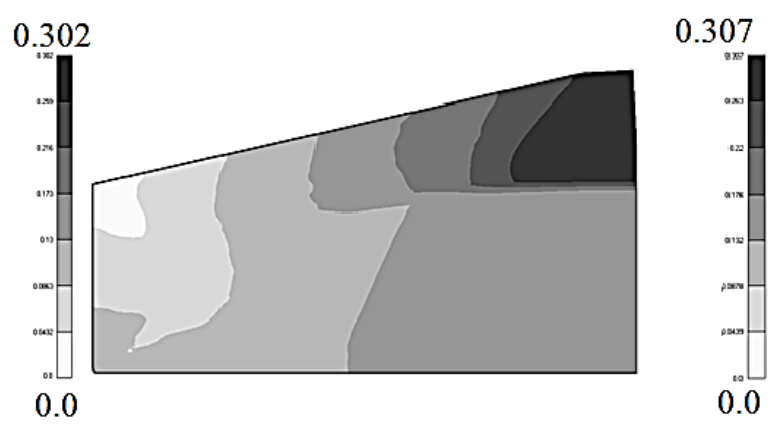

6

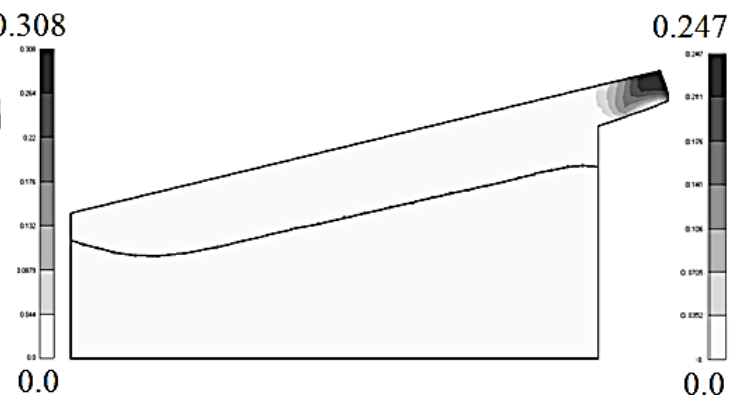

$\Gamma$

Рис. 5. Распределение пористости на последовательных этапах (а, б, в, г) штамповки биметаллической заготовки, начальная пористость верхнего слоя была равна 0,3, нижнего - 0,15

В начале штамповки более интенсивно уплотняется верхний слой. Затем процесс уплотнения распространяется на нижний слой.

К моменту, когда начинается вытекание материала в компенсатор, минимальная пористость слоев - у внутренней поверхности заготовки, максимальная - в области компенсатора.

В конце процесса деформирования величина пористости минимальна и ее распределение по объёму заготовки практически равномерно. Таким образом, получение двухслойного биметаллического изделия становится возможным.

В то же время следует отметить искривление поверхности раздела между слоями. В результате толщина верхнего слоя около внутренней поверхности заготовки меньше, чем в остальной части изделия.

\section{ВЫВОДЫ}

В современной промышленности широко применяются детали, имеющие кольцевидную форму. Отдельную группу таких изделий составляют детали с конусообразной поверхностью. Эффективным методом их получения является горячая штамповка порошковых пористых заготовок 
Использование заготовок с небольшими плюсовыми допусками по массе обуславливает наличие в конструкции штампа специального компенсатора для размещения избыточного объема металла.

Предварительное компьютерное моделирование процесса деформирования в штампе с кольцевым коническим компенсатором порошковых заготовок позволило установить ряд закономерностей их уплотнения и формоизменения.

В процессе штамповки происходит радиальное течение материала в направлении от центра. На заключительной стадии деформирования материал достигает поверхности матрицы и начинается вытекание излишка металла в компенсатор. При этом материал полностью заполняет полость штампа, происходит доуплотнение зон затрудненной деформации и выравнивание плотности по объёму изделия.

В процессе деформирования биметаллических заготовок было установлено, что возможно вытекание менее прочного нижнего слоя из-под верхнего. Для предотвращения этого эффекта предложено использовать заготовки с разной начальной пористостью слоев.

\section{СПИСОК ИСПОЛЬЗОВАННОЙ ЛИТЕРАТУРЫ}

1. Носенко М. І. Розробка способів гарячої деформації порошкових заготовок при отриманні деталей конструкційного призначення / М. І. Носенко, В. О. Павлов // Нові матеріали і технологї в металургї̈ та машинобудуванні. - 2013. - № 1. - С. 72-77.

2. Рябичева Л. А. Термомеханический режим штамповки детали сложной формь из порошкового материала / Л. А. Рябичева, О. П. Гапонова // Обработка материалов давлением: сб. науч. трудов. - Краматорск : ДГМА, 2010. - № 1 (22). - С. 188-193.

3. Баглюк Г. А. Сравнительный анализ деформированного состояния пористых заготовок при штамповке в закрытом и открытом штампах / Г. А. Баглюк, А. И. Хоменко // Обработка материалов давлением : сб. науч. трудов. - Краматорск : ДГМА, 2012. - № 2 (31). - С. 147-153.

4. Горохов В. М. Объемная штамповка порошковых материалов / В. М. Горохов, Е. А. Дорошкевич, А. М. Ефимов, Е. В. Звонарев. - Минск : Навука і техніка, 1993. - 272 с.

5. Кун Х. А. Основныле принципь штамповки порошковых заготовок / Х. А. Кун // Порошковая металлургия материалов специиального назначения. - М. : Металлургия, 1977. - C. 143-158.

6. Дорофеев В. Ю. Структура и свойства порошкового материала, формируемого при горячей штамповке с элементами выдавливания / В. Ю. Дорофеев // Порошковая металлургия. - 1985. - № 7. - С. $23-27$.

7. Баглюк Геннадий Анатольевич. Научно-технологические приниипь получения изделий из порошковых материалов на основе гетерогенных железоуглеродистых сплавов с повышенной износостойкостью : дис. ... д-ра техн. наук : 05.16.06 «Порошковая металлургия и композиционные материаль» / Баглюк Геннадий Анатольевич. - Киев, 2004. - 486 с.

8. Патент № 29502 Україна, МПК В 22 F 3/02. Штамп для гарячої штамповки порошкових заготовок / Баглюк Г. А., Позняк Л. О., Мажарова Г. Ю., Капля С. М. (Украӥна). - № 29502 ; опубл. 15.11.2000, Бюл. № 6.

9. Штерн М. Б. Модифицированные модели деформирования порошковых материалов на основе пластичных и труднодеформируемых порошков / О. В. Михайлов, М. Б. Штерн // Вісник національного технічного університету України «Київький політехнічний інститут». Серія : Машинобудування. - 2011. - № 62. - C. 13-19. P. 215-226.

10. Green R. G. A plasticity theory for porous solids / R. G. Green // Int. Journ. Of Mech. Sci. - 1972. - V. 14. -

11. Shima S. Plasticity theory for porous metals / S. Shima, M. Oyane// Int. Journ. Of Mech. Sci. - 1976. V. 18. - P. 285-291.

12. Михайлов О. В. Учет разносопротивляемости растяжению и сжатию в теориях пластичности пористых тел / О. В. Михайлов, М. Б. Штерн // Порошковая металлургия. - 1984. - № 5. - С. 11-17.

13. Зенкевич О. Метод конечных элементов в технике : пер. с англ. / О. Зенкевич. - М. : Мир, 1975. - 541 c.

14. Баглюк Г. А. Повышение эффективности уплотнения пористых заготовок за счет интенсификацุии сдвиговых деформаџий / Г. А. Баглюк // Реологія, структура, властивості порошкових та композиційних матеріалів: зб. наук. працьь. - Луцькк : РВВ ЛДТУ, 2004. - С. 35-48.

\section{REFERENCES}

1. Nosenko M. I. Rozrobka sposobiv garjachoi' deformacii' poroshkovyh zagotovok pry otrymanni detalej konstrukcijnogo pryznachennja / M. I. Nosenko, V. O. Pavlov // Novi materialy $i$ tehnologii' v metalurgii' ta mashynobuduvanni. - 2013. - № 1. - S. 72-77.

2. Rjabicheva L. A. Termomehanicheskij rezhim shtampovki detali slozhnoj formy iz poroshkovogo materiala / L. A. Rjabicheva, O. P. Gaponova // Obrabotka materialov davleniem: sb. nauch. trudov. - Kramatorsk : DGMA, 2010. - № 1 (22). - S. 188-193. 
3. Bagljuk G. A. Sravnitel'nyj analiz deformirovannogo sostojanija poristyh zagotovok pri shtampovke v zakrytom i otkrytom shtampah / G. A. Bagljuk, A. I. Homenko // Obrabotka materialov davleniem : sb. nauch. trudov. Kramatorsk : DGMA, 2012. - № 2 (31). - S. 147-153.

4. Gorohov V. M. Ob\#emnaja shtampovka poroshkovyh materialov / V. M. Gorohov, E. A. Doroshkevich, A. M. Efimov, E. V. Zvonarev. - Minsk : Navuka i tehnika, 1993. - 272 s.

5. Kun H. A. Osnovnye principy shtampovki poroshkovyh zagotovok / H. A. Kun // Poroshkovaja metallurgija materialov special'nogo naznachenija. - M. : Metallurgija, 1977. - S. 143-158.

6. Dorofeev V. Ju. Struktura i svojstva poroshkovogo materiala, formiruemogo pri gorjachej shtampovke s jelementami vydavlivanija / V. Ju. Dorofeev // Poroshkovaja metallurgija. - 1985. - № 7. - S. $23-27$.

7. Bagljuk Gennadij Anatol'evich. Nauchno-tehnologicheskie principy poluchenija izdelij iz poroshkovyh materialov na osnove geterogennyh zhelezouglerodistyh splavov s povyshennoj iznosostojkost'ju : dis. ... d-ra tehn. nauk: 05.16.06 «Poroshkovaja metallurgija i kompozicionnye materialy» / Bagljuk Gennadij Anatol'evich. - Kiev, 2004. $486 \mathrm{~s}$.

8. Patent № 29502 Ukrai'na, MPK V 22 F 3/02. Shtamp dlja garjachoi' shtampovky poroshkovyh zagotovok / Bagljuk G. A., Poznjak L. O., Mazharova G. Ju., Kaplja S. M. (Ukrai'na). - № 29502 ; opubl. 15.11.2000 , Bjul. № 6.

9. Shtern M. B. Modificirovannye modeli deformirovanija poroshkovyh materialov na osnove plastichnyh i trudnodeformiruemyh poroshkov / O. V. Mihajlov, M. B. Shtern // Visnik nacional'nogo tehnichnogo universitetu Ukraïni «Kï̈vs'kij politehnichnij institut». Serija : Mashinobuduvannja. - 2011. - № 62. - S. 13-19.

10. Green R. G. A plasticity theory for porous solids / R. G. Green // Int. Journ. Of Mech. Sci. - 1972. - V. 14. -

11. Shima S. Plasticity theory for porous metals / S. Shima, M. Oyane// Int. Journ. Of Mech. Sci. - 1976. V. 18. - P. 285-291.

12. Mihajlov O. V. Uchet raznosoprotivljaemosti rastjazheniju i szhatiju v teorijah plastichnosti poristyh tel / O. V. Mihajlov, M. B. Shtern // Poroshkovaja metallurgija. - 1984. - № 5. - S. 11-17.

13. Zenkevich O. Metod konechnyh jelementov v tehnike : per. s angl. / O. Zenkevich. - M. : Mir, 1975. - 541 s.

14. Bagljuk G. A. Povblshenye эffektyvnosty uplotnenyja porystblh zagotovok za schet yntensyfykacyy sdvygovblh deformacyj / G. A. Bagljuk // Reologija, struktura, vlastyvosti poroshkovyh ta kompozycijnyh materialiv: zb. nauk. prac'. - Luc'k: RVV LDTU, 2004. - C. 35-48.

Михайлов О. В. - д-р техн. наук, вед. науч. сотруд. ИПМ им. И. Н. Францевича НАН Украины;

Михайлов А. О. - аспирант НУПТ;

Баглюк Г. А. - - д-р техн. наук, ст. науч. сотруд., зам. дир. ИПМ НАНУ;

Штефан Е. В. - д-р техн. наук, проф., зав. каф. НУПТ.

ИПМ им. И. Н. Францевича НАН Украины - Институт проблем материаловедения имени И. Н. Францевича Национальной академии наук Украины, г. Киев.

НУПТ - Национальный университет пищевых технологий, г. Киев.

E-mail: olmi2012@bigmir.net 